\title{
'It's Like You Are Trapped in a Small Place': \\ Language Skill Acquisition and Settlement Outcomes of Ageing Cambodian Refugees
}

\author{
Shamette Hepburn, MSc., MSW, RSW, PhD \\ School of Social Work, York University \\ 4700 Keele Street, M3J 1P3, Canada
}

Tel: 1-416-736-2100Ｅ-mail: hepburns@yorku.ca

Received: July 26, $2020 \quad$ Accepted: August 12, $2020 \quad$ Published: August 19, 2020

doi:10.5296/ijsw.v7i2.17422 URL: https://doi.org/10.5296/ijsw.v7i2.17422

\begin{abstract}
Language skill acquisition is one of the main challenges encountered by refugees and immigrants entering and transitioning to a new society. In Canada, adult newcomers' language education is primarily tasked to English as a Second Language (ESL) programs. These programs aim to provide English language training, preparation for the labour market and integration into Canadian society. This paper presents findings of a larger qualitative study that explored the experiences of 15 community-dwelling Cambodian Canadians (aged 55 and older) in northwest Toronto. Drawing on critical transnationalism and postcolonialism, it examines Cambodian Canadians' reflections on their language skill acquisition and integration vis-à-vis the education and migration regimes which form part of the resettlement bureaucracy supporting these activities and processes. Decades after participating in language education programs, ageing Cambodian Canadians' narratives reveal that inadequate resources and support have resulted in lower than desired language skill acquisition and differential inclusion within their communities.
\end{abstract}

Keywords: Khmer/Cambodian Canadians, Refugees, Language skill acquisition, Settlement outcomes, Critical transnationalism, Postcolonialism

\section{Introduction}

Refugees' cross-cultural adaptation and integration are ongoing processes that require them to make personal, social, and economic adjustments in differential contexts (Das, Dubus, \& Silka, 2013; Ostrander, Melville, \& Berthold, 2017). When they transition to a new country, education (formal or informal) is a key component supporting these processes and can be a barrier or facilitator of long-term integration. This paper focuses on the experience of 
language skill acquisition and its impact on everyday life among first-generation Khmer or Cambodian Canadians living in northwest Toronto. Most Cambodian refugees who arrived in Canada after 1979 entered as 'designated class' refugees through federal government and private sponsorship programs. According McLellan (2009) many who were accepted for resettlement did not have formal education and were regarded as the least educated among Indochinese refugees. On arrival in Canada, more than 90 percent of Cambodian refugees did not speak French or English, the country's official languages and only two percent reported that they had finished high school (McLellan, 2009). Using the narratives of 15 Cambodian Canadians (aged 55 and older) this paper explores their later life adaptations as community-dwelling older adults, almost three decades after their initial resettlement. In particular, the paper engages with critical transnationalism (Hepburn, 2018) and postcolonialism in order to critically examine their reflections on language skill acquisition and integration vis-à-vis the education and migration regimes aimed at supporting their initial resettlement and long-term integration.

\section{Cambodians' Resettlement in Canada: A Brief Overview}

The latest Canadian census indicates that the total population of Khmer or Cambodian Canadians is approximately 38,490, with the majority living in the provinces of Quebec and Ontario (Statistics Canada, 2017). Approximately 6,000 (2,740 males and 3,205 females) Cambodian Canadians live in Toronto. Moreover, there is a lack of adequate census data on ageing Cambodian Canadians, many of whom have been in Canada for more than 30 years. This lack of data has been attributed to the populations' language barriers, difficulty understanding and completing census forms and the community's reluctance to disclose personal information (McLellan, 2009). The main studies on Cambodian Canadians are drawn from McLellan's (1995, 2004, 2009) qualitative work which examine issues of resettlement, social service provision, settlement resources, inter-generational relations and the overall well-being of the population. Following the fall of the Khmer Rouge regime in 1979, thousands of Cambodians fled to Vietnam and Thailand. During the 1980s and 1990s, 300,000 resettled in the United States, the United Kingdom, New Zealand and Australia; Canada accepted 18,602 refugees between 1980 and 1992 (McLellan, 1995, 2004, 2009).

In Canada, the majority of Cambodian refugees initially settled in larger urban areas such as Montreal and Toronto. Some refugees preferred smaller cities which they believed would be more conducive to language skill acquisition, finding jobs and integrating into communities (McLellan, 1995, 2004, 2009). Cambodian refugees who settled in Ontario cities

such as Hamilton, Kingston, London, Ottawa, Toronto and Windsor were impacted by the limited availability of Khmer translators. Given that language support was essential for their engagement in routine activities such as communicating with medical professionals or school staff, limited availability would have far-reaching impact on their everyday life and overall social participation (McLellan, 2009). Further, barriers to English as a Second Language (ESL) training resulted in resettlement challenges, such as social isolation. McLellan (2009) observes that English language acquisition was a significant impediment to resettlement among older Cambodian Canadians. As an earlier life course trajectory, it would function to curtail their ability to readily build the social capital required for integration and inclusion.

Inadequate language support was among a range of issues faced by refugees and may have 
been symptomatic of a general lack of coordination of support services. Social work practitioners are implicated in the provision of inadequate services as they often have the lead role (initiating and coordinating supports) among interdisciplinary professional teams collaboratively responding to refugees' needs (George, 2012). Similarly, Ostrander et al. (2017) explain that social workers have displayed a significant lack of understanding of the needs of Cambodian refugees. Given social workers' position in Canada's resettlement bureaucracy, questions emerge about whether a displayed lack of understanding of refugees' needs is reflective of the refugee-host tensions that flow from social categories such as of race, class and gender, and which further compound the settlement process. In order to mitigate refugees' prolonged instability, Ostrander et al. (2017) challenge social work practitioners to develop holistic approaches aimed at understanding refugees' well-being, while simultaneously promoting appropriate policies aimed at supporting their long-term settlement and inclusion within their communities.

\section{Education and Language Support Services}

In the contemporary welfare state, the educational needs of adult newcomers have been met by programs offering basic language, literacy, skills training and professional education (Guo 2015). Programs are typically offered by school boards, post-secondary institutions, non-governmental organizations and the private sector. In Canada, ESL programs were first offered by the federal government in 1947 (Guo, 2015; McDonald, George, Cleghorn, \& Karenova, 2008). In 1978, the Canada Employment and Immigration Commission, under the auspices of the federal government, rolled out a national language training project which complemented the Canadian Job Strategies program. This program targeted newcomers and Indigenous people who lacked English and French proficiency, which presented as a barrier to employment. The program offered a training allowance to heads of households, who were typically male (Guo, 2015). Assimilationist ethos flowing from the Citizenship Act in 1947 sought to replace newcomers' language and culture with English and French languages and to facilitate Anglo-Saxon acculturation. In 1986, after a legal challenge and complaints of gender discrimination, the federal government created the Settlement Language Training Program (SLTP), which was not focused on newcomers' preparation for the labour market. It provided access to 500 hours of basic English training, day care funding and transportation to support mainly to women (Guo, 2015).

In the early 1990s, a shift in ESL program objectives occurred. Once overtly focused on assimilation and nation building, objectives were now attuned to integration. In 1992, the Language Instruction for Newcomers (LINC) program was created as a key element of the Immigration Plan for 1991-1995 under a federal integration strategy. LINC programs marked a shift in language training for employability to one focused on integration (Guo, 2015). The programs provide access to 900 hours of instruction and focus more on the functions of language such as survival level skills. Program participants are taught and evaluated in a framework of task-based assessments and 12 Canadian Language Benchmarks (CLBs) measuring proficiency. LINC certification is a standardized measure for employers in Canada. However, it has been criticized for separating language from literacy. For example, in its delivery, instructors separate learners' process of learning to read from their process of learning a second language (Duguay, 2012). Another program, English Language Training 
(ELT), which started in 2003, would provide language training geared toward specific professional fields such as nursing and engineering (Boyd \& Cao, 2009). It also focused on interpersonal skill development and cross-cultural communication in order to support the maintenance of employment. ELT programs provide in-class instruction, support job searches, and provide unpaid work placements (Guo, 2015).

The relationship between language training and employment, according to Guo (2015), represents a contemporary shift in government focus from assimilation to employability and integration. This may have accounted for the truncated language supports first-generation Cambodians received, as they were in the cross-currents of varying education policy and program changes during their early resettlement period. A significant degree of a lack of prior formal learning was evident among Cambodian refugees arriving in Canada in the 1980s and 1990s with more than half of men and the majority of women being functionally illiterate in the Khmer language (McLellan, 2009). In an analysis of Employment and Immigration Canada data, McLellan (2009) explains that among the 18602 Cambodian refugees who were resettled in Canada between 1980 and 1992, only 8 percent reported either French or English fluency. Of the group, 31 percent or 5,678 had no formal education and 54 percent or 9980 had received some primary education in Cambodia; and 3 percent or 624 reported completing education levels equivalent to grade 9 . The number reporting a completion of some secondary school was 1513 or 8 percent; only 393 or 2 percent had completed secondary school; while 488 or 3 percent had some post-secondary education (Employment and Immigration Canada 1980-92; McLellan 2009). These significant language and educational needs and challenges should have signaled to social workers and other members of Canada's resettlement bureaucracy of the need for highly specialized service provision and long-term support.

McLellan (2009) observes that 'low educational and literacy statistics clearly demonstrated the Cambodians' need for extensive language and job skills training to facilitate secure employment and adaptation' (p. 46). Yet, despite their pre-migration and settlement challenges, ESL training was provided to refugees for the first six months after their arrival in Canada, was offered to the heads of households and discontinued after they found employment. Agencies providing services to Cambodian refugees in the 1980s reported serving refugee households that were typically led by women. These households were in distress and were experiencing family isolation with no access to ESL and other supports. Many refugees had already been in Canada for almost a decade before ever coming in contact with a service worker (McLellan 2009). Difficulty with second-language acquisition has persisted among ageing cohorts of Cambodian Canadians and has become a protracted resettlement issue. Critical ethnic scholars such as Sunera Thobani (2007, p. 3) discuss the peripheral treatment of refugees in relation to the positioning and overrepresentation of the national subject as embodying 'the quintessential characteristics of the nation and the personification of its values, ethics, and civilizational mores'. Thobani (2007) explains that in the master narrative of the nation, 'exalted subjects' are in the centre, others, especially those who are racialized such as refugees, are relegated to the margins. Refugees have unfortunately been seen as drawing upon the nation's resources, instead of being seen as contributing members of society. The paradigm shift that this paper calls for problematizes the racial, economic, and class conditions for citizenship within the context of language 
acquisition and inclusion.

\section{Conceptual Framework}

First-generation Cambodians are among increasing cohorts of racialized diasporic older adults in Canada. Their reflection on their life course trajectories prises apart the various considerations of how adult education has been a central part of their incorporation into Canadian society, rendering these considerations visible for critical examination. Thus, a critical framing of Cambodian Canadians' experiences with adult education and resettlement is warranted in order to account for their long-term settlement outcomes. I draw on an emergent critical transnationalism and postcolonial theory for analyzing implicit and explicit expectations of language education policies and programs.

Critical transnationalism assists in the animation and interrogation of Cambodian Canadians' negotiation with the national, for example, policies flowing from the multiculturalism of difference such as adult education geared towards newcomers, and the transnational, for example, their mobile itineraries and minutiae of their everyday lives within their communities (Ezra \& Rowden, 2006; Hepburn, 2019; Hepburn \& Coloma, 2019). The perspective is attentive to questions of politics, and power, and how these may, in turn, uncover new forms of neocolonialist practices in settlement practices. For example, language acquisition has been associated with positive outcomes such as 'community, self- and socioeconomic worth, mobility, access to information and knowledge' and of course adaptation and integration (Graff, 1979, p. xv). However, Wickens and Sandlin (2007) explain that critical literacy researchers, have observed that there are incongruities associated with the process. Literacy/language education and migration regimes are inherently political and can be tools of oppression when they foster deficit perspectives and engage in social control (Freire, 1970; Lankshear \& Knobel, 2006; Luke, 2003; Quigley, 1997). As former refugees, first-generation Cambodians contend with globalizing processes that have implications for democracy, citizenship and nationalism (Anthias 2012). Thus, they interface with national borders which are policed formally and informally as a barrier against undesirable others. This policing, Anthias (2012) explains, is done through 'migration controls, racism and the desire for the integration and management of minorities within, while excluding others on the outside and the inside' (p. 103). Similarly, Morrice (2019) notes that everyday bordering systems devise and utilize processes and practices for sorting and excluding migrants. Within the settlement process, literacy and language education are positioned to manage and facilitate the liminal integration of immigrants and refugees in Canada. Coloma (2017) contends that racialized and diasporic subjects, such as the study's participants, continually seek to resist the marginalization that is ascribed to the migration endeavor. He explains that they do so by asserting their presence in the metropolitan body politic and resist oppression by seeking to generate critical, transformative knowledges about their own communities. Coloma (2017) states:

For racialized minority, diasporic, and colonized subjects and for those in solidarity with them, to work against epistemicide is to generate and enact a paradigmatic shift in the curriculum of empire and global migration. It is fundamentally a critical project that calls into question received ideas, destabilizes interpretations, imagines other possibilities, and struggles for $[\ldots]$ societal transformation. (p. 100) 
Postcolonial theory 'focuses on the difference and disjunctions, as well as the differential distribution of life chances grounded in the spatial dichotomy of what is identified as centre and periphery' (Kunow, 2016, p. 101). The theory contends with the persistent influence of hegemony in constructing or determining positional differences. Contemporary migration is a disruptive cultural force within globalization and inserts difference within relatively stable national imaginaries. Hall (2003) contends,

Unlike earlier phases, where the problems of religious, social, and cultural difference were held at a safe distance from metropolitan homelands, contemporary migration intrudes directly into, disturbs, challenges and subverts metropolitan cultural space. It projects the vexed issue of pluralism and difference into the settled monocultural spaces of the Western metropolis. It has produced an epistemic rupture, generating the thematics of a new problematic - that of the postcolonial moment. (Hall, 2003, p. 196)

Fundamentally, postcolonial critique serves to destabilize dominant ideology for purposes of analyzing historical and contemporary events from the perspective of the subaltern (Hepburn, 2018; Wickens \& Sandlin, 2007). Therefore, the centering of first-generation Cambodian Canadians' narratives is an essential aspect of this process (Gramsci, 1992; Spivak, 1988). Significantly, education and schooling in colonial contexts are largely 'designed to meet the conceptions and needs of the colonizers rather than the colonized, and this influenced the amount, type and availability of education' (Bray 1993, 334). As is customary, colonial educational systems destroy existing indigenous knowledge, culture and educational systems. The programs, course materials, curricula, assessment and pedagogical practices that support and direct the settlement of newcomers, are fashioned according to the desires of the colonial power and undermines the authenticity of other cultures and discourses (Watson, 1994; Wickens \& Sandlin 2007).

\section{Study Design}

This paper utilizes data from one aspect of a larger York University-funded Mapping Transnational Livelihoods study, which is focused on later-life experiences of immigrants and refugees in Toronto. The qualitative study examined the narratives of 15 Cambodian Canadian older adults (aged 55 and older) in northwest Toronto. All participants were born in Cambodia and had entered Canada as refugees after living in refugee camps in Thailand or Vietnam. Within the sample, there were 14 females and one male. The research protocol was approved by the York University's Office of Research Ethics. Purposive sampling was used to address the study's central question and data collection was conducted on site at the Jane and Finch Family and Community Centre (JFFCC) over a five-month period between November 2019 and March 2020. For analytical purposes, I explored the following research question: How do Cambodian Canadians perceive their earlier engagement with educational and language supports that were aimed at supporting their resettlement and long-term integration in Canada?

Through in-depth interviews, I explored participants' experiences with education and language supports earlier in their settlement process and impact of these experiences in later life. In-depth interviews are purposeful interactions between an investigator and research participants and are aimed at understanding lived experiences and the meanings attributed to such experiences (Eastmond, 2007; Fryer et al., 2011). The participants' language and literacy 
capacity varied. Translation was provided by the JFFCC programme workers who engage with participants during their weekly adult day support activities and assist in connecting them to the wider Toronto community. Language expression and understanding are fundamental to in-depth research interviews, the representation of data and the communication process between researcher and participants (Fryer, 2019). Participants spoke a range of languages such as Khmer and Mandarin, they often had low literacy levels in these languages and even lower literacy levels in English and French. Interviews were conducted in English and Khmer with the aid of a Cambodian Canadian translator. Rather than establishing criteria excluding participants based on language capacity or literacy levels, the research design reflected both the diversity of contemporary communities and the goal of facilitating inclusivity (Feldman et al., 2008; Fryer, 2019). As a critical gerontological social worker, I adopted a reflexive approach to the research process and built rapport with the participants and the language interpreters over several months prior to starting data collection (Edwards et al., 2005; Fryer, 2019). This was essential to the research process given that I am not a member of the Cambodian Canadian community.

Data analysis followed grounded theory's iterative process of moving back and forth between empirical data and emerging analyses. This process made the collected data more focused and the analysis more theoretical (Charmaz, 2014). Both data collection and analysis proceeded simultaneously with each guiding the other. Grounded theory methods facilitated an open-ended approach to studying the experiences of participants and to building systematic checks into both data collection and analysis. The approach is especially generative when there is limited understanding of a particular group and when their perspectives or voices are rarely sought (Bergold \& Thomas, 2012).

\section{Findings}

Participants' narratives underscored later life experiences which have been circumscribed by earlier experiences with education programs. They described challenging and protracted resettlement processes that persist as well as instances of agency. Two themes which emerged from participants' narratives are: (1) Resettlement Complexities and Language Acquisition and (2) Liminal Integration

\subsection{Resettlement Complexities and Language Acquisition}

All participants reported having knowledge of ESL programs when they arrived in Canada, which suggests they may have also received information about access and eligibility. One 69-year-old participant who arrived in Canada in 1993 explained that she had a strong desire to learn English but felt overwhelmed by the course requirements and the process of filling out forms to start the program. She explained, 'I wanted to attend ESL but they wanted too many documents. I had to sign up too many forms so I just gave up.' The participant stated that she would later go on to learn English vicariously through her children as they moved through the school system. Similarly, one 56-year-old participant who arrived in 1992 reported completing Grade 12, the highest level reportedly attained by participants in the study. She stated,

I completed Grade 12 in Cambodia. I attended communication classes in Cambodia for a short time. It helped me a little bit and I built on it from words I learned in Cambodia. I did 
ESL for a time but I got pregnant and stopped.

Research has shown that newcomer women typically seek language education after their children are settled or have completed early childhood education, by which time they may be ineligible for LINC programs (Duguay, 2012; Kilbride et al., 2008). Evidence of complex learning needs was also revealed in participants' narratives. Combined with pre-settlement challenges such as trauma, functional illiteracy, transitioning to life in Canada, ESL program support would have added on to an already complicated resettlement process. Explaining the challenge of having to work and learn a new language simultaneously, one 64-year-old participant who arrived in Canada in 1991 stated,

When I came, I did not have a good feeling because I did not know "ABCD” or nothing. I only went to ESL for two years. When you get letters, you don't know how to read them, it makes life hard when you don't have English. I took ESL but I had to go to work after, so sometimes I would forget what they said at school.

While many participants mentioned being aware of ESL supports within the community, none reported having any access to specialized language supports given their low levels of literacy. Despite these challenges, many participants were able to acquire jobs, primarily in factories. For many, those early factory jobs would be their sole employment during their working life in Canada. Other participants who came to Canada having some knowledge of English, explained how they were able to utilize those language skills to scaffold their ESL programming. One 67-year-old participant who arrived in Canada in 1991 explained, 'When I came there were a lot of obstacle but thank goodness there was ESL support so that I could understand how the society works.' The ability to understand the society's mores is integral to social inclusion and participation. Kilbride et al. (2008) has outlined the importance of culture in language education and why the learning and settlement needs of newcomers may not be met by generic approaches that do not attend to complex differences and existing capabilities.

One participant explained that while in a refugee camp in Thailand, she understood that getting an early grasp of English would help her to adjust to life in Canada. Therefore, she started learning English before being resettled in Canada. Her prior exposure to English aided in a comparatively smoother transition in relation to other refugees who were functionally illiterate and had no prior education in English. She commented,

I did some English in Thailand. I didn't come here to learn "ABC". I had that already so when I came and got the ESL I could just laugh because I had my English in Thailand. Some people waited to get the English here but I knew it was better to start learning once we knew we would get the chance to come to Canada. When they interviewed me in Thailand, I even did it in English and they were saying "wow, you are ready for Canada!"

The participant displayed significant agency in trying to learn English before arriving in Canada and this supported her preparation to resettle in Canada. Like the majority of participants in the study, she did not undertake further study after ESL programming. This is not unusual given the intention of program to support employability. Once participants were able to learn enough functions of the language to secure employment, their formal English education ended. As the literature indicates, first-generation Cambodians arrived with varying 
educational qualifications (McLellan, 2009). However, the narratives presented in this study also indicate that participants had varying learning needs and styles that would have required specialized or nuanced interventions to support not only their English acquisition but also their literacy in Khmer. ESL programs did not effectively address linguistic contexts related to the Khmer language nor the educational history and literacy of participants. Questions emerge about how to integrate already marginalized people into the Canadian polity. Based on participants' narratives, it is evident that generic language programs have not been effective in supporting resettled populations with complex pre- and post-migration challenges.

\subsubsection{Liminal Integration}

Most participants were limited-English-proficient. Factors internal and external to them as learners appear to have impacted their attainment of the language proficiency levels required for acceptable degrees of social participation and inclusion in their communities (Duguay 2012). However, to compensate, first-generation Cambodians have high levels of community-based service utilization which support their independent living within the community. For example, most utilize adult day programming at the Jane and Finch Family and Community Centre's (JFFCC) Unity in Diversity program in northwest Toronto, where they receive support from bi-lingual Khmer support workers who facilitate access to mainstream services. In this setting, they are able to build community and engage in cooperative learning activities which align with their Khmer-Buddhist traditions.

Everyday life challenges persist and participants report that they still experience barriers navigating the community. One 69-year-old participant who came to Canada in 1993 explained her difficulty making purchases and have to rely on assistance. She stated,

I needed clothes and I went to buy some. They don't fit but I can't return them because I don't have enough English, so I have to keep them. I want to get winter shoes but I have to wait until I get someone to go with me to buy them because I don't have the language.

Another participant aged 71 years, and who arrived in 1991, explained that instead of English, she uses Mandarin to engage with professionals as she is not proficient in English and there is still a lack of adequate Khmer supports in Toronto. She stated, I speak Mandarin to my doctor. That's what we do to be able to communicate where people don't speak Khmer.' Other participants reported that their limited language proficiency has made their later life challenging and potentially isolating. Given this, they seek out fellow Cambodians as they do not have the language skills to expand their social networks. The participant further stated,

If you don't have the language, it's like you are trapped in a small place. You are out and about in the community and everything but you are really out and about in a very small place.

The participants' description of limited English proficiency is synonymous with limited integration within the community and society. This is significant given the length of time since first-generation Cambodians were initially resettled in Canada. More so, language proficiency is central to the economic integration of newcomers in Canada and bolsters their ability to access higher education and labour market opportunities (Chiswick \& Miller, 2007). One 65-year-old participant who arrived in Canada in 1983 explained that government investment in education supports for Cambodians was inadequate and she alluded to the fact 
that this may have hindered her ability to fully participate in Canadian society. She stated, I only have some ESL. I didn't learn a lot of English and I didn't do anything else after that because I had to work. Education is the way to the community and support. It is the way to get ahead. It is sad that they didn't do more for us.

Research has shown that immigrants who do not have proficiency in one of Canada's official languages in the workplace lag in earnings, with earning gaps more significant for women than men (Aydemir \& Skuterud, 2005). It is possible to draw parallels between Cambodians' experiences and those of Vietnamese refugees, a similar group of South East Asians. When Vietnamese refugees arrived in Canada between 1972 and 1980, the majority reported that they did not speak English or French (Hou, 2017). In the first two years after arrival, many reported improvements in language acquisition especially among refugees living in Montreal. Hou (2017) suggests that it is possible that better educated refugees settled in Montreal, as they quickly found jobs and continued their education. In the three decades after arrival, Vietnamese refugees lowered the poverty gap between themselves, other immigrants and members of the general population. Older refugees who had found jobs within the first year or two of arrival exited the labour market after a short period of time due to old age or ill health. Members of prime age groups (aged 18 to 44 years) worked for longer periods and built the social and economic capital to close the poverty gap (Hou, 2017). Cambodians refugees endured significant levels of trauma and questions emerge about the nature of supports they received in comparison to other groups who have been able to build the social and economic capital to achieve greater levels of integration. There are no extant studies on Cambodians' ESL program exit proficiency and employment successes. According to Duguay (2012) a lack of accountability has made it difficult to measure newcomers' language proficiency when they enter Canada, take a limited amount of ESL programs and then enter the workforce. However, this study's findings reveal that ageing Cambodian Canadians understand their second language acquisition, and social and economic integration to be limited.

\section{Discussion and Implications for Social Work}

This study examined the experiences of 15 ageing Cambodian Canadians living in northwest Toronto. Drawing on critical transnationalism and postcolonial theory, the research has important implications for the revisioning of ESL education supports for refugees in order to improve accessibility and thus, create better conditions for the settlement and integration of non-English speaking diasporic peoples. Through the use of interviews, the study's findings make a case for the need for specialized and sustained ESL education and support across the life course. This qualitative approach, particularly through the quotidian anecdotes, humanizes the struggle of non-English/French speaking migrants that quantitative methods inadequately communicate.

An analysis of participants' retrospective accounts is timely given that most first-generation Cambodian Canadians were initially resettled almost three decades ago. Their narratives highlight the importance of language education and proficiency as key facets of the integration of resettled populations in Canada. The study's findings illustrate how a lack of access to specialized education has significantly limited social and economic integration in Canadian society. Language and literacy programs which are based on benchmarks or generic 
approaches are typically designed to facilitate newcomers' social and economic integration. However, Gibb (2015) explains that programs are largely designed and delivered based on universal or national understandings of language and literacy. Therefore, they diminish immigrants' and refugees' embodied ways of knowing and being (Morrice, 2019). Cambodian refugees, upon resettlement in Canada, were incorporated in a language regime driven by government-constructed competency standards (Guo, 2015). The study's participants did not describe content or instructional delivery of ESL programs and there was no account of how their knowledge of Khmer was used to scaffold their learning experiences. This is hardly surprising given that the standardized assessments utilized in English language education 'leave little space for pluralistic ways of knowing and denies the centrality of culture, social relations, and locality in people's daily literacy and language practices' (Gibb, 2015, p. 59).

According to Gibb (2015) standards based on reading, writing, listening and speaking proficiency, invariably position language as mechanistic and ignore cultural, political and social norms associated with it. Thus, in a globalized world, language, literacy and issues of newcomer integration in host societies highlight both difference and systems of inequality (Blommaert, 2010; Gibb, 2010; Morrice, 2019). Significantly, first-generation Cambodian Canadians' experiences have revealed that literacy and language are intertwined with social power relations which relegate them to the margins of Canadian society (Thobani, 2007).

While education is regarded as a pathway to human security, it is no longer considered a social commodity by which individuals can improve the quality of their lives (Wickens \& Sandlin, 2007). Instead, it is an economic investment and neocolonialist paradigms determine who is worthy of such an investment. Guo and Maita (2019, p. 2) explain that '...in the modern colonial world that we live in, knowledge and learning are never neutral ... western knowledge is ... upheld as neutral and universal vis-à-vis what is backward and inferior coming from former colonies'. Language acquisition and lifelong learning have been regarded as indicators of quality of life, yet dominant conceptions render them as economic investments based on colonial imperatives. The lack of specialized attention to Cambodian Canadians is part of the colonial project, in which educational investments are considered in relation to economic return and uneven power distribution. Economic globalization and neoliberal policies which gained momentum in the 1990s have served to shift the humanistic ethos associated with life-long learning to a focus on flexibility and skills training to meet ever-changing labour market needs (Guo \& Maita, 2019). Thus, 'utilitarian discourse ... represented by the "skills" agenda' (Elfert, 2018, p. 28) are embedded within learning and migration regimes, creating hierarchical differences of race, gender and class within curricula and pedagogy (Guo \& Maita, 2019).

Critical transnational and postcolonial analyses reveal a distorted framing of migration and integration which create a paradoxically limited role for education - one that is based on stabilizing Canada's sense of a national identity, securing its borders and framing migrant integration (Morrice, 2019). To counter this role, which produces exclusionary practices that result in the marginalization of learners, migrant education should be interrogated. Its pedagogical approaches should centre on intercultural dialogue and the structural barriers to integration should be removed (Guo \& Maitra, 2019; Morrice, 2019). Language regimes and 
educational programs directed at first-generation Cambodians have perpetuated exclusion and models of social control. Guo (2015) proposes a recognitive adult education as a paradigm shift that promotes inclusivity, fosters opportunities for self-development and self-expression, and embraces social and cultural diversity. Fraser (2000, p. 113) contends that recognition entails 'examining institutionalized patterns of cultural value for the effects on the relative standing of social actors'. Thus, to be misrecognized is to be denied full social participation and to be limited by institutionalized subordination (Fraser, 2000; Guo, 2015). A recognitive adult education considers transnational migrant flows and rejects efforts to assimilate newcomers into dominant social, cultural and educational norms. Significantly, it positions the process of integration as a two-way process in which newcomers are involved in the creation and implementation of programs serving them.

Ostrander et al. (2017) recommends that social workers implement a structural competency approach within a trauma-informed system of support for refugees. This approach would provide social workers with the capability to account for microsystem interactions between clients and social workers but to also attend to the structural inequalities and social determinants that constrain refugees' experiences. When reinforced by a human-rights approach, a decolonial social work practice, supported by refugees' families, social networks and community organizations, can provide the critical community support required for achieving settlement and integration. The challenges raised by ageing Cambodian Canadians have revealed the colonial, racial and cultural frameworks that mediate migrants' knowledge, skill acquisition, settlement and integration. These frameworks and related outcomes have implications for social work practice and research given the prominent role of practitioners in migration regimes. To support ageing refugees, practitioners should position themselves to work within a postcolonial context. Masson and Smith (2020) explain that a decolonial approach should address: 1) domains of being (such as identity, humanism and dignity); 2) domains of power (such as critical conscientisation and empowerment); and 3) domains of knowledge (such as language, culture and history).

By adopting this approach, practitioners can become cognizant of local and transnational concerns of individuals and communities. In reference to participants' settlement outcomes, language and migration regimes into which Cambodian Canadian were incorporated have played out in their social, economic, and political spheres. Limited language acquisition and supports have impacted ageing Cambodian Canadians' well-being and long-term settlement outcomes. As they seek to maintain independence within their communities, potential social isolation is concern. Further, limited access to resources and professionals can have negative consequences for their well-being and their ability to remain independent within their communities. Similarly, persistent low-income and limited ability to participate in political and civic affairs curtail their ability to self-advocate. Yet, they display tremendous agency in seeking support and navigating their communities as best they can; thus, demonstrating the efficacy of their daily literacy practices and embodied knowledge (Gibb, 2015). Social work must rethink its ongoing complicity in nation-building practices within migration regimes, especially in the case of ageing Cambodian Canadians. A decolonial approach to social work practice and research with this community would reject Eurocentric approaches that are not useful at the local level; it would centre local cultural values, knowledge and practices; and 
reclaim individual and collective narratives (Masson \& Harms, 2020).

\section{Conclusion}

This community-based research contributes to existing limited literature on ageing Cambodian Canadians. Specifically, this paper explored first-generation Cambodians' experiences with language education and the latter's impact on long-term settlement outcomes. Language skill acquisition continues to be an essential aspect of the resettlement process. Findings revealed that difficulty with second-language acquisition has persisted among ageing cohorts of Cambodian Canadians and has become a protracted resettlement issue. However, through their every-day literacy practices, they demonstrate significant agency in navigating everyday life circumstances. Drawing on critical transnationalism and postcolonial theory, the paper problematizes the racial, economic, and class conditions for citizenship within the context of language acquisition and inclusion. It advances an analysis of the language and migration regimes which prepared first-generation Cambodians for their transition into Canadian society and which have paradoxically facilitated their liminal incorporation. This retrospective glance comes at an important phase in Cambodian Canadians' migratory life course, almost three decades after their initial resettlement in Canada.

Acknowledgement: This study was funded by a York University Minor Research Grant. The author wishes to thank the study's participants and the staff of the Jane and Finch Family and Community Centre's (JFFCC) Unity in Diversity Senior's Program in Toronto.

Compliance with Ethical Standards: This research was approved by the Office of Research Ethics, York University.

Conflict of Interest: The author declares no conflict of interest.

\section{References}

Anthias, F. (2012). Transnational mobilities, migration research and intersectionality: Towards a translocational frame. Nordic Journal of Migration Research, 2(2), 102-110. https://doi.org/10.2478/v10202-011-0032-y

Aydemir, A., \& Skuterud, M. (2005). Explaining the deteriorating entry earnings of Canada's immigrant cohorts, 1966-2000. Canadian Journal of Economics, 38, 641-672. https://doi.org/10.1111/j.0008-4085.2005.00297.x

Bergold, J., \& Thomas, S. (2012). Participatory research methods: A methodological approach in motion. Forum Qualitative Sozialforschung/Forum: Qualitative Social Research, 13(1), 1-1.

Blommaert, J. (2010). The sociolinguistics of globalization. New York: Cambridge University Press. https://doi.org/10.1017/CBO9780511845307

Boyd, M., \& Cao, X. (2009). Immigrant language proficiency, earnings, and language policies. Canadian Studies in Population, 36(1), 63-86. https://doi.org/10.25336/P6NP62

Bray, M. (1993). Education and the vestiges of colonialism: Self-determination, neocolonialism and dependency in the South Pacific. Comparative Education, 29(3), 333-348. https://doi.org/10.1080/0305006930290309

Charmaz, K. (2014). Constructing grounded theory (2nd ed.). Thousand Oaks: Sage. 
Chiswick, Barry R., \& Paul, W. M. (2013). The Impact of Surplus Skills on Earnings: Extending the Over-education Model to Language Proficiency. Economics of Education Review, 36, 253-275. https://doi.org/10.1016/j.econedurev.2013.07.008

Coloma, R. S. (2017). We are here because you were there: On curriculum, empire, and global migration, Curriculum Inquiry, 47(1), 92-102. https://doi.org/10.1080/03626784.2016. 1254505

Das, M., Dubus, N., \& Silka, L. (2013). Decades after resettlement: Later life experiences of Cambodian refugees. Humanity \& Society, 37(4), 327-345. https://doi.org/10.1177/ 0160597613510705

Duguay, A.L. (2012). The School of Life: Differences in U.S. and Canadian Settlement Policies and Their Effect on Individual Haitian Immigrants' Language Learning, TESOL Quarterly, 46(2), 306-333. https://doi.org/10.1002/tesq.23

Eastmond, M. (2007). Stories as lived experience: Narratives in forced migration research. Journal of Refugee Studies, 20(2), 248-64. https://doi.org/10.1093/jrs/fem007

Edwards R., Temple B., \& Alexander C. (2005). Users' experiences of interpreters: The critical role of trust. Interpreting, 7(1), 77-95. https://doi.org/10.1075/intp.7.1.05edw

Elfert, M. (2018). UNESCO's utopia of lifelong learning: An intellectual history. New York: Routledge. https://doi.org/10.4324/9781315278131

Ezra, E., \& Rowden, T. (2006). General introduction: What is transnational cinema? In E. Ezra, \& T. Rowden (Eds.), Transnational cinema: The film reader (pp. 1-12). London, UK: Routledge.

Feldman, S., Radermacher, H., Browning, C., Bird, S., \& Thomas, S. (2008). Challenges of recruitment and retention of older people from culturally diverse communities in research. Ageing \& Society, 28(4), 473-93.

Freire, P. (1970). Pedagogy of the oppressed. New York: Continuum.

Fryer, F.C. (2019). An approach to conducting cross-language qualitative research with people from multiple language groups. In P. Liamputtong (Ed.) Handbook of Research Methods in Health Social Sciences (pp. 1653-74). Singapore: Springer. https://doi.org/10. 1007/978-981-10-5251-4_38

George, M. (2012). Migration traumatic experiences and refugee distress: Implication for social work practice. Clinical Social Work Journal, 40, 429-437. https://doi.org/10.1007/ s10615-012-0397-y

Gibb, T. (2015). Regimes of language skill and competency assessment in an age of migration: the in/visibility of social relations and practices, Studies in Continuing Education, 37(3), 251-266. https://doi.org/10.1080/0158037X.2015.1043986

Graff, H. J. (1979). The literacy myth: Literacy and social structure in the nineteenth-century city. New York: Academic Press.

Gramsci, A. (1992). Prison notebooks. New York: Columbia University Press.

Guo, S. and Maita, S. (2019). Decolonising lifelong learning in the age of transnational migration. International Journal of Lifelong Education, 38(1), 1-4. https://doi.org/10.1080/ 02601370.2018 .1561534 
Guo, S., \& Maita, S. (2019). Theorising decolonising lifelong learning in the age of transnational migration: Anti-colonial and anti-racist perspectives. International Journal of Lifelong Education, 38(1), 5-19. https://doi.org/10.1080/02601370.2018.1561534

Guo, S. (2015). The changing nature of adult education in the age of transnational migration: Toward a model of recognitive adult education. In S. Guo, \& E. Lange (Eds.) Transnational migration, social inclusion and adult education (pp. 7-17) San Francisco: Jossey Bass. https://doi.org/10.1002/ace.20127

Guo, Y. (2015). Language policies and programs for adult immigrants in Canada: Deconstructing discourses of integration. In S. Guo, \& E. Lange (Eds.) Transnational migration, social inclusion and adult education (pp. 41-51) San Francisco: Jossey Bass. https://doi.org/10.1002/ace.20130

Hall, S. (2003). Creolization, diaspora, and hybridity in the context of globalization. In O. Enwezor, C. Basualdo, U. M. Bauer, S. Ghez, S. Maharaj, M. Nash, \& O. Zaya. Creolite and creolization: Documenta 11 platform 3 (pp. 180-198). Ostfildern, Germany: Hatje Cantz.

Hepburn, S. (2019). Signalling the end of the migration journey: Exploring transnational ageing narratives on residential selection. Journal of International Migration and Integration https://doi.org/10.1007/s12134-019-00737-1

Hepburn, S., \& Coloma, R. S. (2019). Ageing transmigrants and the decolonization of life course. International Journal of Lifelong Education, 38(1), 44-66. https://doi.org/10.1080/ 02601370.2018.1513428

Hepburn S. (2018). Residential selection at retirement: A visual ethnography exploring the later life mobilities of ageing Jamaican Canadian transmigrant. Doctoral dissertation, University of Toronto, Ontario. Available from ProQuest Dissertations \& Theses Global database.

Hou, F. (2017). The resettlement of Vietnamese refugees across Canada over three decades. (Working Paper No 188). Helsinki: UNU-WIDER. https://doi.org/10.35188/UNUWIDER/2017/414-8

Fraser, N. (2000). Rethinking recognition. New Left Review, 3, 107-120.

Kilbride, K., Tyyskä, V., Berman, R., Ali, M., Wougang, I., Guruge, S., \& Cazzola, R. (2008). Reclaiming voice: Challenges and opportunities for immigrant women learning English. Ottawa, Ontario, Canada: Canadian Council on Learning.

Kunow, R. (2016). Postcolonial theory and old age: An explorative essay. Journal of Aging Studies, 39, 101-108. https://doi.org/10.1016/j.jaging.2016.06.004

Lankshear, C., \& Knobel, M. (2006). New literacies: Everyday practices and classroom learning (2nd ed.). Buckingham, UK: Open University Press.

Luke, A. (2003). Literacy and the other: A sociological approach to literacy research and policy in multilingual societies. Reading Research Quarterly, 38(1), 132-141.

Masson, F., \& Smith, L. (2020). Colonisation as collective trauma: fundamental perspectives for social work. In T. Kleibl, R. Lutz, N. Nowoo, B. Bunk, A. Dittmann, \& B. Seepamore (Eds.) The Routledge Handbook of Postcolonial Social Work (pp. 13-26). New York: Routledge. 
McDonald, L., George, U., Cleghorn, L., \& Karenova, K. (2008). An analysis of second language training programs for older adults across Canada. Toronto: University of Toronto. McLellan, J. (2009). Cambodian refugees in Ontario: Resettlement, religion, and identity. University of Toronto Press. https://doi.org/10.3138/9781442697713

McLellan, J. (2004). Cambodian refugees in Ontario: Religious identities, social cohesion and transnational linkages. Canadian Ethnic Studies, 36(2), 101-18.

McLellan, J. (1995). Cambodian refugees in Ontario: An evaluation of resettlement and adaptation. Toronto: York Lanes Press. Quigley, B. A. (1997). Rethinking literacy education. San Francisco: Jossey-Bass.

Morrice, L. (2019). Abyssal lines and cartographies of exclusion in migration and education: Towards a re-imagining. International Journal of Lifelong Education, 38(1), 20-33. https://doi.org/10.1080/02601370.2018.1489425

Ostrander, J., Melville, A., \& Berthold, S. M. (2017). Working with refugees in the US: Trauma-informed and structurally competent social work approaches. Advances in Social Work, 18(1), 66-79. https://doi.org/10.18060/21282

Spivak, G. (1988). Can the subaltern speak? In L. Grossberg \& C. Nelson (Eds.), Marxism and the interpretation of culture (pp. 271-313). New York: Routledge. https://doi.org/10. 1007/978-1-349-19059-1_20

Statistics Canada. (2017). Immigration and Ethnocultural Diversity Highlight Tables, 2016. (Catalogue No. 98-402-X2016007). Retrieved from https://www12.statcan.gc.ca/census-recensement/2016/dp-pd/hlt-fst/imm/index-eng.cfm

Thobani, S. (2007). Exalted subjects: Studies in the making of race and nation in Canada. Toronto: University of Toronto Press.

Watson, K. (1994). Technical and vocational education in developing countries: Western paradigms and comparative methodology. Comparative Education, 30(2), 85-97. https://doi.org/10.1080/0305006940300202

Wickens, C. M., \& Sandlin, J. A. (2007). Literacy for what? Literacy for whom? The politics of literacy education and neocolonialism in UNESCO and World Bank-sponsored literacy programs. Adult Education Quarterly, 57(4), 275-292. https://doi.org/10.1177/0741713 607302364

\section{Copyright Disclaimer}

Copyright reserved by the author(s).

This article is an open-access article distributed under the terms and conditions of the Creative Commons Attribution license (http://creativecommons.org/licenses/by/4.0/). 